\title{
Biochemical and physiological characterization of the GTP-binding protein Obg of Mycobacterium tuberculosis
}

Smitha J Sasindran, Sankaralingam Saikolappan, Virginia L Scofield, Subramanian Dhandayuthapani

\begin{abstract}
Background: Obg is a highly conserved GTP-binding protein that has homologues in bacteria, archaea and eukaryotes. In bacteria, Obg proteins are essential for growth, and they participate in spore formation, stress adaptation, ribosome assembly and chromosomal partitioning. This study was undertaken to investigate the biochemical and physiological characteristics of Obg in Mycobacterium tuberculosis, which causes tuberculosis in humans.

Results: We overexpressed M. tuberculosis Obg in Escherichia coli and then purified the protein. This protein binds to, hydrolyzes and is phosphorylated with GTP. An anti-Obg antiserum, raised against the purified Obg, detects a $55 \mathrm{kDa}$ protein in immunoblots of $M$. tuberculosis extracts. Immunoblotting also discloses that cultured M. tuberculosis cells contain increased amounts of Obg in the late log phase and in the stationary phase. Obg is also associated with ribosomes in M. tuberculosis, and it is distributed to all three ribosomal fractions $(30 \mathrm{~S}, 50 \mathrm{~S}$ and 70 S). Finally, yeast two-hybrid analysis reveals that Obg interacts with the stress protein UsfX, indicating that $M$. tuberculosis Obg, like other bacterial Obgs, is a stress related protein.

Conclusions: Although its GTP-hydrolyzing and phosphorylating activities resemble those of other bacterial Obg homologues, M. tuberculosis Obg differs from them in these respects: (a) preferential association with the bacterial membrane; (b) association with all three ribosomal subunits, and (c) binding to the stress protein UsfX, rather than to RelA. Generation of mutant alleles of Obg of $M$. tuberculosis, and their characterization in vivo, may provide additional insights regarding its role in this important human pathogen.
\end{abstract}

\section{Background}

GTP-binding proteins are found in all living organisms, and they play critical roles in fundamental processes such as cell proliferation, development, signal transduction and protein translation $[1,2]$. In general, these proteins are hydrolase enzymes that convert GTP into GDP, allowing transfer of the GTP terminal phosphate group to a target protein. As a consequence of this transfer, the highly conserved domains (G1, G2, G3, G4 and G5) of GTP-binding proteins undergo conformational changes that are detected by downstream effector proteins $[3,4]$, leading to specific outcomes.

\footnotetext{
* Correspondence: dhandayutha@uthscsa.edu Regional Academic Health Center and Department of Microbiology and Immunology, The University of Texas Health Science Center at San Antonio, Edinburg, Texas, 78541, USA
}

Comparison of bacterial genomes, across all taxa, has shown that at least eleven highly conserved GTP-binding proteins are present in prokaryotes [5]. Among these, the Obg/GTP1 subfamily of monomeric GTP binding proteins is of special significance, because these proteins exist not only in prokaryotes but also in eukaryotes [6]. The gene encoding Obg was first identified in Bacillus subtilis [7]. Obg orthologues were subsequently discovered in Streptomyces griseus [8], Streptomyces coelicolor [9], Caulobacter crescentus [10], Echerichia coli [11] and Vibrio harveyi [12]. While orthologues of Obg in $C$. crescentus and $V$. harveyi are known as CgtA, the orthologue of Obg in E. coli is called ObgE. Bacterial Obg display intrinsic GTPase activity and autophosphorylate with GTP, as does the eukaryotic signaling molecule Ras, which is a GTP-binding protein. Because of 
this, Obg has been considered to be a potential bacterial signaling molecule $[8,13]$.

Several published studies have attributed diverse functions to Obg in different bacterial species. In B. subtilis, for example, Obg is necessary for the transition from vegetative growth to stage 0 or stage II of sporulation [14]. Sporulation is a complex process in this species and is controlled by multiple components including phosphorelay. It appears that Obg is one of the components that modulate the sporulation-related phosphorelay by an undefined mechanism [15]. In addition to its activity in B. subtilis, Obg plays critical roles in developmental events in other bacteria, e.g. aerial mycelium formation and sporulation in Streptomyces griseus [8] and S. coelicolor [9]. In these two species, sporulation has a tight relationship with changes in the intracellular GTPto-GDP ratio, and bacterial Obgs are considered to be stress sensors for intracellular GTP-GDP changes reflecting energy balance in the cells. It has been proposed that high levels of Obg-GTP maintain vegetative division of sporulating bacteria and prevent sporulation, while high levels of Obg-GDP promote sporulation [9].

Obg is required for the activation of B. subtilis SigB in response to physical stress. This activation occurs via Obg's physical interaction with upstream Rsb regulators of SigB [16]. Further, the GTP-binding pocket of crystallized Obg of B. subtilis contains guanosine 5' diphosphate, 3' phosphate (ppGpp) [16]. ppGpp is a guanosine nucleotide known as an alarmone in bacteria. Alarmones are produced in response to amino acid starvation, and they act as signaling intermediates to slow cell growth or to initiate stress-induced differentiation pathways, including sporulation. In bacteria, the synthesis of ppGpp is performed by two enzymes, called RelA and SpoT [17-19]. In E. coli, SpoT is one of the proteins known to interact with Obg [20]. In V. cholerae, depletion of the Obg homologue CgtA results in a global gene expression pattern reflecting the low-nutrient stress reaction called the "stringent" response [21]. In $V$. cholerae, CgtA interacts with $\mathrm{SpoT}$, and this interaction decreases SpoT activity leading to the repression of the stringent response [21]. Another interesting example of Obg's association with stress comes from the pathogen Legionella pneumophila, where its expression is elevated during intracellular survival [22].

Recent studies indicate that Obg associates with ribosomes of bacteria and interacts with ribosomal proteins. In $B$. subtilis, Obg coelutes with ribosomal proteins and interacts specifically with the ribosomal protein L13, a component of the $50 \mathrm{~S}$ ribosomal subunit [23]. The Obg orthologues of C. crescentus [24], V. harveyi [25] and E. coli $[20,26]$ also cofractionate with the $50 \mathrm{~S}$ ribosomal subunit. Finally, bacterial Obg has also been implicated in chromosomal partitioning [11] and replication regulation [27].

Mycobacterium tuberculosis is an intracellular pathogen and causative agent of tuberculosis in humans. The recent emergence of multidrug (MDR-TB) and extremely drug resistant (XTR-TB) M. tuberculosis strains now poses serious threats to people in the developing world [27], and combating the disease requires the development of new anti-tuberculosis drugs. However, design and development of new drugs for TB largely depends upon the identification and characterization of novel drug targets in $M$. tuberculosis. The fact that Obg is an essential protein for growth in bacteria, including M. tuberculosis [28], and its association with ribosomes makes it a potential target for future antimicrobials $[29,30]$. Thus, this study was undertaken to understand the basic properties of Obg of M. tuberculosis.

\section{Results and Discussion}

Overexpressed $M$. tuberculosis Obg binds to, and hydrolyzes, GTP

A single copy of the gene coding for Obg $(R v 2440 c)$ is present in the genome of $M$. tuberculosis, between the genes proB $(R v 2439 c)$ and rpmA $(R v 2441 c)$. The deduced amino acid sequence of the $M$. tuberculosis Obg protein shows significant similarities with the Obg proteins of B. subtilis, S. coelicolor and other bacterial species (Additional file 1). To study the properties of Obg of $M$. tuberculosis, the plasmid construct pTBOBGE was made to overexpress Obg in E. coli. Log phase E. coli cells (strain BL21) bearing the plasmid pTBOBGE were induced by IPTG to overexpress a protein that migrates at around $55 \mathrm{kDa}$ in SDS-PAGE gels. This overexpressed protein, purified as detailed in the Methods section, showed a single protein in SDS-PAGE (Figure 1A). This was designated as $\mathrm{His}_{10}-\mathrm{Obg}$, to distinguish it from the native, normally expressed Obg protein in M. tuberculosis.

To verify whether the overexpressed Obg of $M$. tuberculosis can interact with GTP, we performed GTPUV-crosslinking experiments [31]. The autoradiogram in Figure $1 \mathrm{~B}$ shows that $\mathrm{His}_{10}$-Obg binds physically to $\left[\alpha^{32} \mathrm{P}\right]$-GTP. Exposure of the reaction mixtures to UV irradiation for 0,30 and $60 \mathrm{~min}$ revealed that binding of GTP with $\mathrm{His}_{10}-\mathrm{Obg}$ is increased between 0 and $30 \mathrm{~min}$ of exposure, but not after $30 \mathrm{~min}$ (Figure 1B). When the reactions were performed in the presence of unlabeled GTP (5 mM), crosslinking of $\mathrm{His}_{10}-\mathrm{Obg}$ to GTP is inhibited, while addition of large amounts of unlabeled ATP $(500 \mathrm{mM})$ have little effect on $\mathrm{His}_{10}$-Obg binding with labeled GTP (Figure 1B). This observation adds to existing evidence that $M$. tuberculosis Obg has an inherent specificity for guanine nucleotides, as do the Obg 


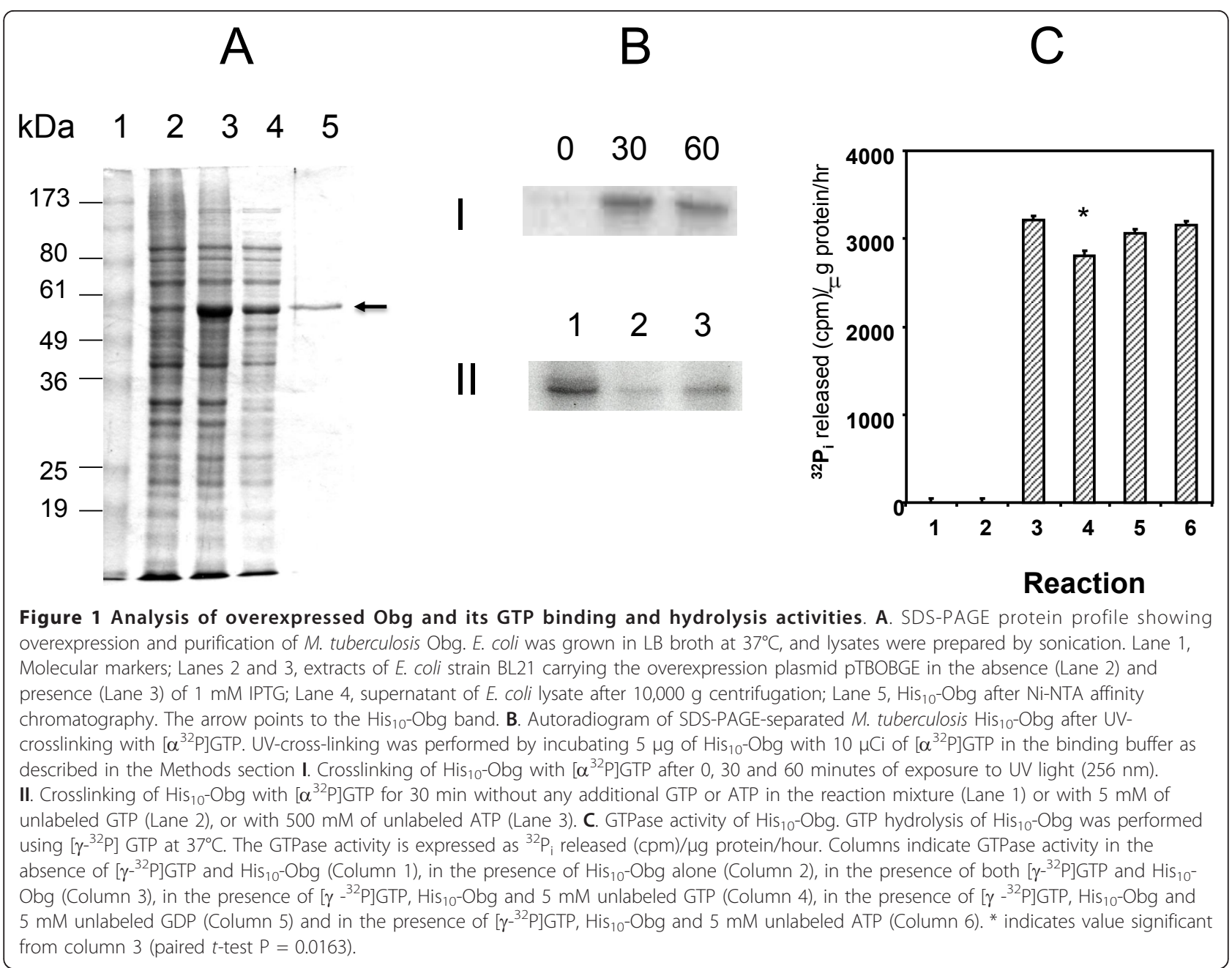

orthologues in C. crescentus [32], B. subtilis [13] and S. griseus [8].

To determine whether the overexpressed Obg can hydrolyze GTP, we incubated $\mathrm{His}_{10}$-Obg with radiolabeled GTP $\left(\left[\gamma_{-}{ }^{32} \mathrm{P}\right] \mathrm{GTP}\right)$, and measured the release of phosphate $\left({ }^{32} \mathrm{P}_{\mathrm{i}}\right)$ after 3 hours. Figure $1 \mathrm{C}$ shows that His $_{10}$-Obg readily hydrolyzes GTP, and that this hydrolysis is inhibited by the addition of unlabeled GTP (5 mM), indicating that unlabeled GTP competes with labeled GTP for the enzyme. Addition of unlabeled ATP $(5 \mathrm{mM})$ has no effect on the hydrolysis of labeled GTP (Figure 1C), indicating that Obg hydrolyzes specifically GTP. The effect of cold GTP in inhibiting the hydrolysis of radiolabeled GTP was not as pronounced as its effect in inhibition of GTP crosslinking (Compare Figure 1B and Figure 1C). This is most likely due to the differences in the positions of the radiolabeled phosphates used in these two reactions. While the reaction mixture in the crosslinking experiment (Figure 1B) had $10 \mu \mathrm{Ci}$ $(0.033 \mu \mathrm{M})$ of $\left[\alpha{ }^{32} \mathrm{P}\right] \mathrm{GTP}$, the reaction mixture in the hydrolysis experiment had $25 \mu \mathrm{Ci}(0.040 \mu \mathrm{M})$ of $\left[\gamma-{ }^{32} \mathrm{P}\right]$
GTP. In addition, the incubation times for these two experiments were different ( $1 \mathrm{~h}$ for GTP crosslinking vs. $3 \mathrm{~h}$ for GTP hydrolysis).

\section{Autophosphorylation of $\mathrm{His}_{10}-\mathrm{Obg}$}

Autophosphorylation by GTP is a defining characteristic of eukaryotic GTP-binding proteins, e.g. Ras [33], and of prokaryotic GTP-binding proteins, including Era of E. coli [34] and Obg of B. subtilis (22). We therefore asked whether $\mathrm{His}_{10}$-Obg of M. tuberculosis is autophosphorylated by GTP. Figure 2A shows that purified His $_{10}$-Obg from $M$. tuberculosis is autophosphorylated by $\left[\gamma_{-}{ }^{32} \mathrm{P}\right] \mathrm{GTP}$, in a time-dependent manner. This autophosphorylation is fully dependent upon $\mathrm{Mg}^{2+}$ ions, since reactions conducted in the absence of $\mathrm{MgCl}_{2}$ in the buffer show almost zero phosphorylation activity (Figure 2B). By contrast, no autophosphorylation of His $_{10}$-Obg occurs with $\left[\gamma_{-}{ }^{32} \mathrm{P}\right] \mathrm{ATP}$, even after $60 \mathrm{~min}$ of incubation. Further, addition of unlabeled ATP to the reaction mixture fails to produce any effect on $\mathrm{His}_{10^{-}}$ Obg phosphorylation with $\left[\gamma_{-}{ }^{32} \mathrm{P}\right]$ GTP (Figure 2C). As 


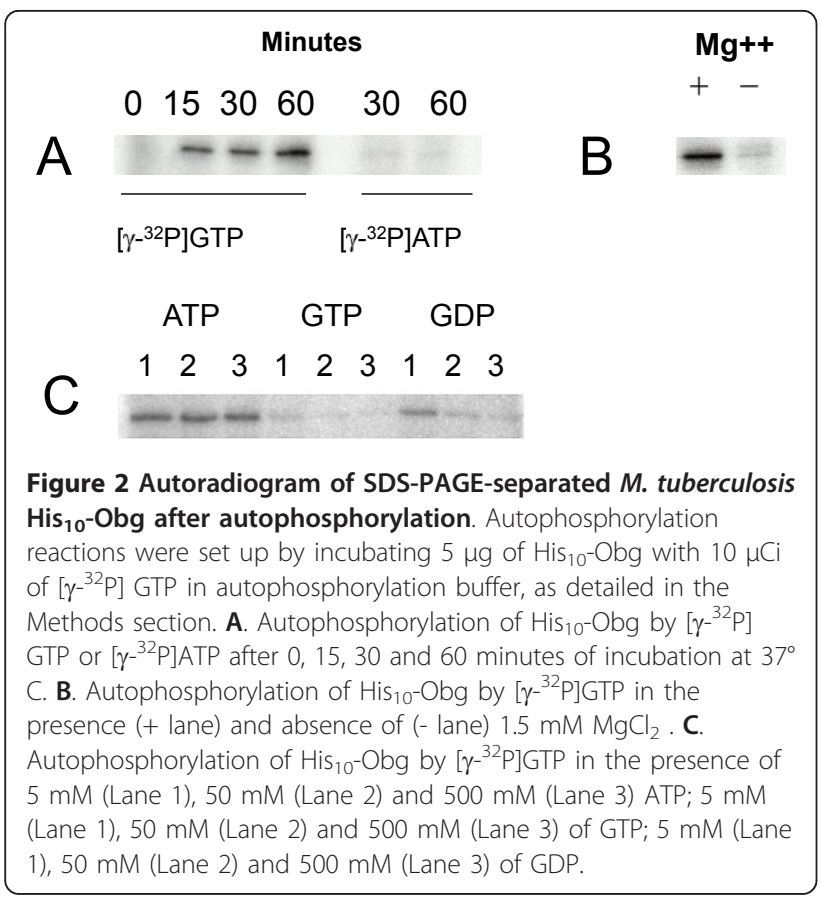

expected, both unlabeled GTP and GDP significantly affect the phosphorylation of $\left[\gamma^{-32} \mathrm{P}\right]$ GTP from His ${ }_{10^{-}}$ Obg (Figure 2C), indicating that both molecules serve as competitors for the phosphorylation site. The eukaryotic Ras protein, which is encoded by the $\mathrm{p} 21^{\text {ras }}$ oncogene, controls cell proliferation, cell stress signaling and apoptosis. The autophosphorylaiton of Ras is independent of its GTPase activity [33], which means that GTP hydrolysis and GTP phosphorylation of Ras occur at two different sites. At present it is unclear whether GTP hydrolysis and GTP-mediated autophosphorylation are independent events for prokaryotic Obgs, and no one has identified a phsophorylation site on any Obg molecule.

\section{Expression of $M$. tuberculosis Obg is growth-dependent, and $\mathrm{Obg}$ is associated with the membrane fraction}

In the sporulating bacterium S. coelicolor, the expression of Obg is regulated developmentally and is linked to the onset of sporulation [9]. By contrast, no such change in expression of Obg occurs in C. crescentus, although it also has a clear developmental cycle involving sporulation [10]. M. tuberculosis is a slow growing bacterium which exhibits neither sporulation nor a developmental cell cycle during its growth in culture. To determine whether the expression of Obg changes during the growth of $M$. tuberculosis in culture, we developed a rabbit anti-Obg antiserum against $M$. tuberculosis $\mathrm{His}_{10}$-Obg, and used it in Western blots of M. tuberculosis protein extracts. This antiserum detects multiple bands in immunoblotted extracts of $M$. tuberculosis, particularly at $55 \mathrm{kDa}$ and $75 \mathrm{kDa}$. To confirm that the $55 \mathrm{kDa}$ protein reacting with antiObg antiserum is in fact Obg, we cloned the coding region of Obg downstream of the $h s p 60$ promoter in the plasmid pMV261, and transformed the resulting construct (pMVOBG) into M. tuberculosis to overproduce Obg. Figure 3A shows that protein extracts of $M$. tuberculosis strains harboring plasmid $\mathrm{pMVOBG}$, but not strains bearing the vector plasmid pMV261, reveal strong $55 \mathrm{kDa}$ protein bands, indicating that the protein at $55 \mathrm{kDa}$ is Obg. Further analysis revealed that the $75 \mathrm{kDa}$ band was a false reactivity due to the second antibody, and that it is not an Obg protein.

Notably, Obg expression does change in cultures of M. tuberculosis over the course of cell growth. Obg expression is markedly increased from early log phase to the stationary phase, with a drop in expression at late stationary phase (Figure 3B). Comparison of the Obg band densities discloses that expression of $\mathrm{Obg}$ at later growth phases $\left(1.645 \mathrm{OD}_{600 \mathrm{~nm}}\right)$ is approximately five fold higher than it is at earlier phases $\left(0.220 \mathrm{OD}_{600 \mathrm{~nm}}\right)$, even before the drop in expression at late stationary phase. Together these results indicate that the expression of Obg in M. tuberculosis is growth-regulated, being increased as the cells begin rapid division in the $\log$ phase, and maintained at high levels until late in the stationary phase. However, whether increased levels of Obg with increased growth of $M$. tuberculosis is due to increased expression of Obg, or to accumulation of Obg, remains to be determined. Obg expression in $E$. coli is also high in log phase growth, but decreased in the stationary phase [26].

In S. griseus [8] and E. coli [11], Obg and its orthologues are found in both the cytoplasmic and membrane fractions. In B. subtilis, however, Obg is mainly associated with the cytoplasm [23]. To determine where Obg resides in $M$. tuberculosis, we isolated soluble and membrane fractions from whole bacteria, and subjected them to immunoblot analysis. Figure $3 \mathrm{C}$ shows that Obg is associated mostly (over 90\%) with the membrane fraction, although detectable amounts are also present in the soluble fraction. In contrast, SigH of $M$. tuberculosis, which was used as a control here, exhibits almost equal distribution between these two fractions. It has been reported that membrane fraction-bound Obg in S. coeliocolor [9] and in E. coli [11] is lost from this fraction if the extraction buffer contains $5 \mathrm{mM}$ EDTA. The buffer we use for $M$. tuberculosis membrane preparations has $10 \mathrm{mM}$ EDTA, however, and Obg is associated with this fraction whether or not EDTA is present (not shown). The EDTA-resistant association of M. tuberculosis Obg to the membrane fraction may reflect a function associated with signaling, and involving divalent cations. Interestingly, Obg is absent from detergent- 


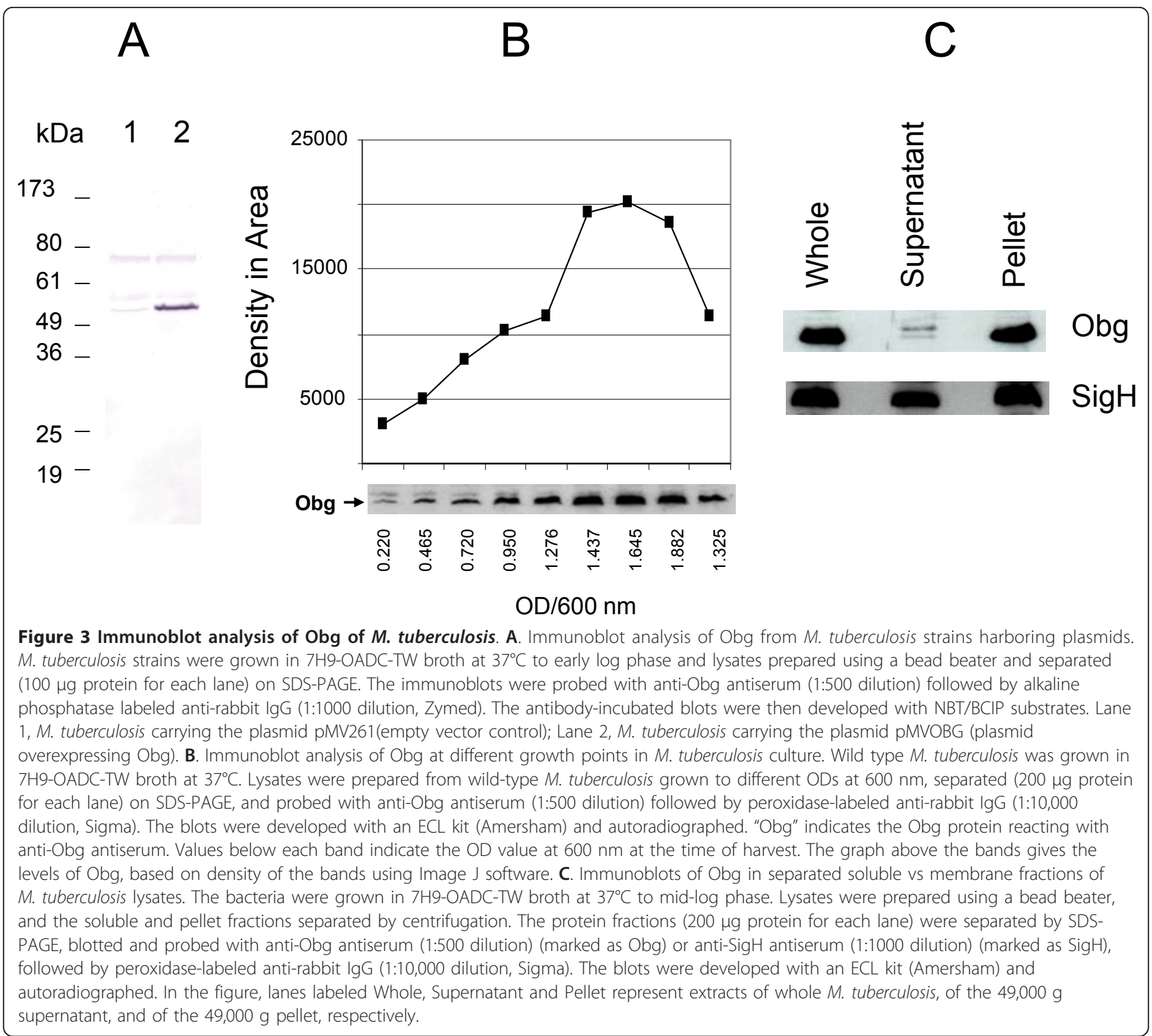

extracted M. tuberculosis membrane [35] and cell wall [36] proteins, suggesting that Obg's association with the membrane may be due to its interaction with other membrane protein(s).

\section{M. tuberculosis Obg associates with ribosomal fractions}

In B. subtilis [23], C. crescentus [24], V. harveyi [25] and E. coli $[20,26]$, Obg has been shown to be associated with ribosomes. In these species, Obg orthologues cofractionate primarily with the $50 \mathrm{~S}$ ribosomal subunit $[23,24,26]$. To determine whether this is also true of $M$. tuberculosis Obg, we isolated ribosomes from $M$. tuberculosis using sucrose gradient centrifugation, as detailed in the Methods section (Figure 4A). Immunoblots of the separated ribosomal fractions (Figure 4B) show that Obg is present in all three $(30 \mathrm{~S}, 50 \mathrm{~S}$ and 70
S) ribosomal fractions, in more or less equal amounts. By contrast, this discrepancy does not appear to be due to improper separation of ribosomal proteins in our sucrose gradient, because analysis of the ribosomal fractions in SDS-PAGE reveals that separation of proteins occurred in the expected line (Additional file 2). The Obg/CgtA of E. coli and C. crescentus has been shown to interact with specific $50 \mathrm{~S}$ ribosomal proteins, and it is the opinion of the investigators in this area that Obg plays a critical role in ribosome assembly. Evidence in support of this hypothesis has been provided with strains producing mutant Obg/CgtA. For example, C. crescentus [37] and E. coli [26] strains expressing mutated Obg have perturbed ribosomal protein profiles. A genetic basis for the involvement of Obg in ribosomal assembly has also been provided in $E$. coli by studies in 


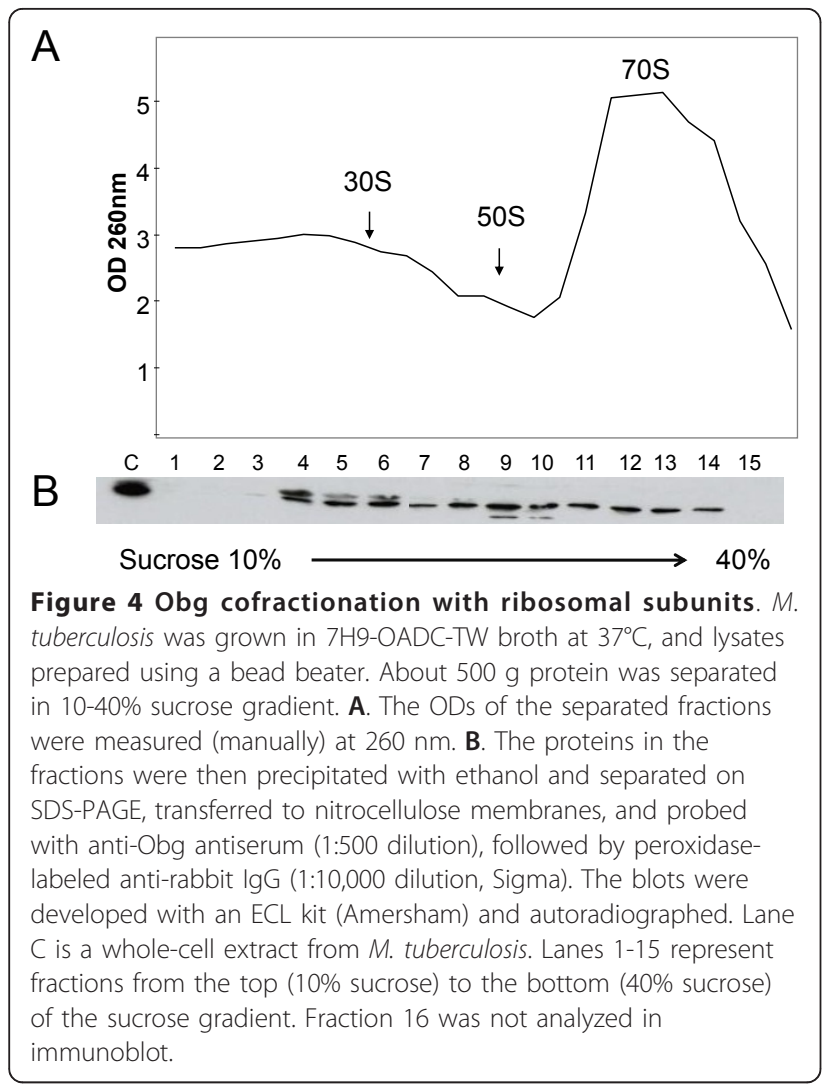

which Obg was overexpressed in an $\mathrm{rrmJ}$ mutant strain [38]. Notably, rrmJ encodes an RNA methyltransferase which is involved in the assembly of $50 \mathrm{~S}$ ribosomes [38]. In line with these observations in bacteria, Obg homologues in yeast (Mtg2P) [39] and mice (Nog1) [40] also show association with ribosome maturation and assembly. Interestingly, in our studies shown here in
Figure 4, lanes 4-6 (30 S region) and lanes 9 and 10 (50 $\mathrm{S}$ region) show an additional band above and below Obg, respectively. We do not know whether these bands represent modified forms of Obg. Work in progress includes studies toward identification of these bands.

\section{M. tuberculosis Obg interacts with UsfX}

Scott et al [41] were the first to observe that B. subtilis Obg interacts with upstream regulators of the stress sigma factor SigB. In this respect, this bacterium's Obg resembles $B$. subtilis RsbT and RsbW, both of which also interact with SigB in this species [41]. More recently, the Obg proteins of E. coli [20] and V. harveyi [21] have been shown to interact with SpoT, a stringent response regulator. Since SigB, RsbW and SpoT-related genes are present in M. tuberculosis, we asked whether M. tuberculosis Obg interacts with any or all of these proteins, in the yeast two-hybrid system. The $M$. tuberculosis genes coding for Obg (Rv2240c), UsfX (homologue of RsbW, Rv3287c), SigF (homologue of SigB of B. subtilis, Rv3286c) and RelA (a stringent response regulator related to SpoT, $R v 2853 c$ ) were cloned in yeast vectors, and transformed into the yeast strain AH109. Table 1 shows that M. tuberculosis Obg strongly interacts with UsfX, but not with the SpoT-related RelA protein. The strength of this interaction is comparable to the interaction of M. tuberculosis UsfX with its cognate sigma factor SigF. In the same experiment, we looked for interaction of $M$. tuberculosis Obg with various other putative anti-anti sigma factors that we have described earlier for this bacterium [42], including RsbU (Rv1364c), RsfA (Rv1365c), RsfB (Rv3687c), Rv0516c, Rv1904 and Rv2638. However, we observed no significant interaction of Obg with any of the above anti-anti sigma factors (data not shown), indicating that the interaction of M. tuberculosis Obg is

Table 1 Interaction of Obg with stress related proteins in the yeast two-hybrid system

\begin{tabular}{|c|c|c|c|c|c|c|}
\hline & \multirow[t]{2}{*}{ *Plasmids } & \multicolumn{3}{|c|}{ SD Minimal Medium } & \multirow{2}{*}{$\begin{array}{l}\text { Mel-I ( } \alpha \text {-gal) in } \\
\text { SD plates }\end{array}$} & \multirow{2}{*}{$\begin{array}{l}\text { Mel-1 ( } \alpha \text {-gal) in } \\
\text { SD broth** }\end{array}$} \\
\hline & & $\begin{array}{l}\text {-Leu/ } \\
\text {-Trp }\end{array}$ & $\begin{array}{l}\text {-His/ } \\
\text {-Leu/-Trp }\end{array}$ & $\begin{array}{l}\text {-Ade/-His/ } \\
\text {-Leu/-Trp }\end{array}$ & & \\
\hline \multirow[t]{2}{*}{1.} & pGADT7-T & + & + & + & +++ & $3.512 \pm 0.709$ \\
\hline & pGBKT7-53 & & & & & \\
\hline \multirow[t]{2}{*}{2.} & pGADT7-T & + & - & - & - & - \\
\hline & pGBKT7-Lam & & & & & \\
\hline \multirow[t]{2}{*}{3.} & pGA3287c & + & + & + & ++ & $2.367 \pm 0.354$ \\
\hline & pGB3286c & & & & & \\
\hline \multirow[t]{2}{*}{4.} & pGA3287c & + & + & + & ++ & $2.172 \pm 0.448$ \\
\hline & pGB2440c & & & & & \\
\hline \multirow[t]{2}{*}{5.} & pGA2853c & + & - & - & - & - \\
\hline & pGB2440c & & & & & \\
\hline
\end{tabular}

Abbreviations. SD, synthetic drop out medium; Ade, Adenine; His, Histidine; Leu, Leucine; Trp, Tryptophan; Mel-1, $\alpha$-galactosidase.

*1-5 indicate plasmids cotransformed into yeast strain AH109 (HIS3, ADE2, MEL1) (Clontech).

${ }^{* *} \alpha$-galactosidase (Mel-1) expressed as Mean \pm SD milli units/A600. Plasmids are described in Table 3. 
limited to UsfX. In light of the known stress response role of UsfX [43], its specific interaction with Obg suggests that Obg plays a role in the M. tuberculosis stress response.

In $B$. subtilis, the activation of SigB in response to stress depends upon its association with, and dissociation from, of RsbW. In turn, this is governed by the phosphorylation state of RsbW [44]. The UsfX protein of $M$. tuberculosis is believed to have similar interaction with its cognate sigma factor SigF [43]. Whether the interaction of Obg with UsfX affects the phosphorylation state of UsfX is unknown. Additional studies assessing the interaction of Obg and UsfX in vitro, and careful examination of phosphate exchange in vivo, may throw light on this part of Obg function. The Obg/CgtA proteins of $E$. coli and $V$. harveyi interact with SpoT, a stringent response regulator and a relative of RelA, which responds to starvation. The fact that Obg of $M$. tuberculosis fails to interact with RelA suggests that the stress response roles of Obg of $M$. tuberculosis differ from those of its homologues in other bacteria.

\section{Overexpression of Obg affects late log phase growth of M. tuberculosis}

Since expression of Obg in M. tuberculosis is growth regulated, we asked whether the presence of unusually high amounts of Obg might effect on the growth of this species. To do this, we followed the growth of $M$. tuberculosis strains bearing the Obg overexpression construct (pMVOBG), vs. strains containing the control plasmid (pMV261), over a period of time. Figure 5 shows that there is no significant difference in growth between the two strains during the early log phase, but that the growth of the Obg-expressing strain is decreased slightly in the late log phase, and that this relative decrease is

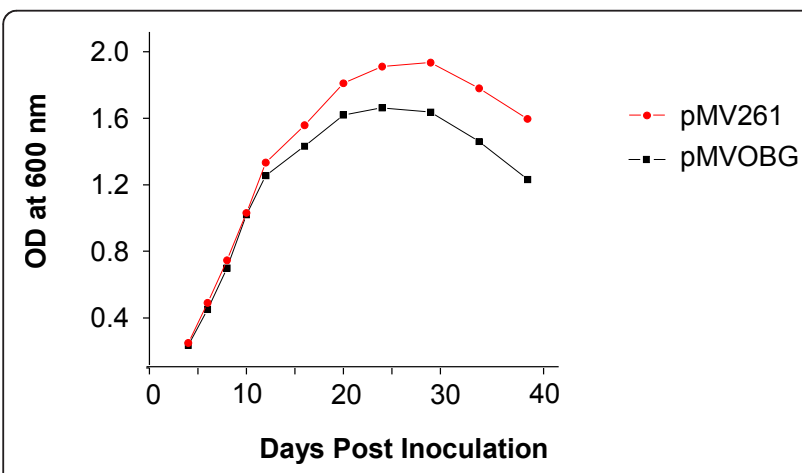

Figure 5 Growth of $M$. tuberculosis strains at different time points. M. tuberculosis was grown in $7 \mathrm{H} 9-\mathrm{OADC}-\mathrm{TW}$ broth at $37^{\circ} \mathrm{C}$. Growth was followed by measuring the OD at $600 \mathrm{~nm}$ using $1 \mathrm{ml}$ aliquots. Closed circles: M. tuberculosis carrying the plasmid pMV26 (empty vector control); squares: M. tuberculosis carrying the plasmid pMVOBG (plasmid overexpressing Obg). The data shown are representative findings from three different. experiments. continued even during the stationary phase (Figure 5). This indicates that overexpression of Obg suppresses cell division to some extent during the late log phase of M. tuberculosis growth. Similarly, increased expression of $E$. coli Obg, through an inducible promoter, suppresses log phase growth [11]. In contrast, overexpression of Obg has little effect on vegetative growth of S. coelicolor, but it significantly affects the development of aerial mycelia by this bacterium [9]. This and other examples have been used to support the proposal that an abundance of GTP-bound Obg is associated with vegetative bacterial growth (cell division), while a relative abundance of GDP-bound Obg promotes stationary development (viability in stationary growth, or differentiation leading to nonvegetative reproduction) [9].

\section{Conclusion}

Our data reveal that $M$. tuberculosis Obg has characteristics that are common to its homologues in other bacteria, in addition to properties that are unique. Generation and characterization of mutant alleles of M. tuberculosis Obg should provide additional insights to the role of Obg in this important human pathogen, and toward identification of antimicrobials that reduce its ability to promote $M$. tuberculosis survival.

\section{Methods}

\section{Bacteria and yeast strains and their growth conditions}

M. tuberculosis H37Rv was grown either in Middlebrook $7 \mathrm{H} 9$ broth medium containing Tween $(0.05 \%)$ and OADC (10\%) (7H9-TW-OADC) broth, or in Middlebrook $7 \mathrm{H} 10$ agar medium containing Tween $(0.05 \%)$ and OADC (10\%) (7H10-TW-OADC). M. tuberculosis strains harboring plasmids were grown in the above media containing the antibiotic kanamycin $(25 \mu \mathrm{g} / \mathrm{ml})$ or hygromycin $(50 \mu \mathrm{g} / \mathrm{ml})$. E. coli strains containing plasmids were grown in LB broth or LB agar plates with the antibiotic(s) ampicillin $(100 \mu \mathrm{g} / \mathrm{ml})$, kanamycin $(25$ $\mu \mathrm{g} / \mathrm{ml}$ ) or both. Unless specified, all bacteria were grown at $37^{\circ} \mathrm{C}$. The yeast strain $\mathrm{AH} 109$ was grown at $30^{\circ} \mathrm{C}$ in YPD broth or in agar supplemented with adenine hemisulphate $(0.003 \%)$.

\section{DNA manipulation}

Chromosomal DNA of M. tuberculosis $\mathrm{H} 37 \mathrm{Rv}$ was isolated using cetyl trimethyl ammonium bromide (CTAB). Plasmid DNA from E. coli was isolated using Qiaprep kit (Qiagen Inc.). PCR reactions were performed as described by Ausubel et al [45], with genomic DNA of M. tuberculosis $\mathrm{H} 37 \mathrm{Rv}$ used as the template for amplifying coding regions of its genes. Oligonucleotide primers (Table 2) were synthesized at the Center for DNA Technology at The University of Texas Health Science Center at San Antonio. 
Table 2 List of primers used in this study

\begin{tabular}{lll}
\hline Primer name & Primer sequence & Gene \\
\hline TBOBG1 & CCGCATATGAAGGGAGCTCGGTGCCT CGG & Obg \\
TBOBG2 & CGTCCGATCCGGACTTCTCATCAGCCATCCCC & Obg \\
TBOBG5 & CCGCAGGATCCGCACACTCCGCAGATGAAGGGAGCTCGGTG & Obg \\
TBOBG6 & ATGAAGGATCCTCGGGCCTCGGTTGTCGATCGGGTC & Obg \\
TBRELAF & ACGCATATGGCCGAGGACAGCAGCTCACGGCGCAAGCG & RelA \\
TBRELAR & ATGGGATCCTGCGTCTGCTCGGCGGAGAAAGCGCG & RelA \\
\hline
\end{tabular}

Underlined nucleotides indicate the restriction sites created in the primers. CATATG, Ndel and GGATCC, BamHI.

To generate an Obg overexpression construct, we amplified the whole gene coding for Obg of $M$. tuberculosis by PCR with primers TBOBG1 and TBOBG2. These primers were designed to have an NdeI site at the 5'nd (TBOBG1) and a BamHI site at the 3'nd (TBOBG2). The DNA fragment obtained was cut with NdeI and BamHI and ligated to a similarly cut $\mathrm{pET} 16 \mathrm{~b}$ vector to create the plasmid pTBOBGE. In addition, we created several other plasmids to express Obg or other proteins in mycobacteria or yeast. Of these, plasmid PMVOBG was created to express Obg through a multicopy plasmid in mycobacteria. For making this plasmid, we first amplified the DNA fragment containing the coding region of Obg of M. tuberculosis by PCR, using the primers TBOBG5 and TBOBG6. The amplified DNA fragment was cut with BamHI and cloned into the BamHI site of pMV261 [46] downstream of the $h s p 60$ promoter. Plasmid pGB2440c, for Obg expression in yeast, was created by cloning the NdeI-BamHI fragment containing obg from pOBGE into NdeI-BamHI-cut pGBKT7. Finally, plasmid pGA2853c, for RelA expression in yeast, was created by cloning the NdeI and BamHI cut DNA fragment containing the relA gene (Rv2853) amplified using primers TBRELAF and TBRELAR, into pGADT7. The cloned DNA fragments in all plasmids were verified by DNA sequencing for their appropriateness. All plasmids that we used in this study are described in Table 3.

\section{Overexpression of $M$. tuberculosis Obg in E. coli and production of antiserum}

The E. coli-overexpressed Obg protein of M. tuberculosis was purified in its native condition. The plasmid construct pTBOBGE was transformed into $E$. coli strain BL21(DE3). A single transformant colony was selected and grown in $2 \mathrm{ml}$ of LB broth overnight. One $\mathrm{ml}$ of this overnight culture was inoculated into $250 \mathrm{ml} \mathrm{LB}$ broth and grown to log phase $(0.350 \mathrm{OD}$ at $590 \mathrm{~nm})$ at $37^{\circ} \mathrm{C}$. IPTG $(1 \mathrm{mM})$ was then added to the culture to induce overexpression of Obg, and the culture was grown for an additional $3 \mathrm{~h}$. Afterwards, E. coli cells were harvested by centrifugation $(5,000 \mathrm{~g}$ for $10 \mathrm{~min}$ at $4^{\circ} \mathrm{C}$ ) and stored overnight at $-80^{\circ} \mathrm{C}$. The pellet was resuspended in $5 \mathrm{ml}$ of lysis buffer $\left(50 \mathrm{mM} \mathrm{NaH}_{2} \mathrm{PO}_{4}\right.$ $\mathrm{pH}$ 8.0, $300 \mathrm{mM} \mathrm{NaCl}, 10 \mathrm{mM}$ Imidazole) containing 1 $\mathrm{mg} / \mathrm{ml}$ of lysozyme, incubated on ice for $30 \mathrm{~min}$ and the cells disrupted by sonication. The lysate was centrifuged at $12,000 \mathrm{~g}$, and the supernatant was loaded on to a $2 \mathrm{ml} \mathrm{Ni-NTA}$ column (Qiagen). After washing the column with $50 \mathrm{ml}$ of wash buffer $\left(50 \mathrm{mM} \mathrm{NaH} \mathrm{PO}_{4} \mathrm{pH}\right.$ 8.0, $300 \mathrm{mM} \mathrm{NaCl}, 20 \mathrm{mM}$ Imidazole), the column-

Table 3 List of plasmids used in this study

\begin{tabular}{|c|c|c|}
\hline Plasmid & Description & Reference/source \\
\hline pCR2.1 & oriColE1, lacZ $\alpha$, Plac, aph, Amp ${ }^{R}$ & Invitrogen \\
\hline pMV261 & oriE, oriM, Phsp60, aph & Stover et al, 1991 \\
\hline pMVOBG & pMV261-Rv2440c full orf & This study \\
\hline pET16b & oriE, lacl, PT7, Amp ${ }^{R}$ & Novagen \\
\hline PTBOBGE & pET16B-Rv2440c full orf & This study \\
\hline pGADT7 & oriColE1, ori2 $\mu, L E U 1, P_{A D H 1}: G A L 4^{\prime}$ activator domain::MCS Amp ${ }^{R}$ & Clontech \\
\hline pGBKT7 & oriColE1, ori2 $\mu, T R P 1, P_{A D H 1}: G A L 4^{\prime}$ binding domain::MCS Km ${ }^{R}$ & Clontech \\
\hline pGADT7-T & SV40 large T-antigen $(84-708)$ in pGADT7 & Clontech \\
\hline pGBKT7-53 & Murine $\mathrm{p} 53_{(72-390)}$ in $\mathrm{pGBKT7}$ & Clontech \\
\hline pGBKT7-Lam & Human lamin $\mathrm{C}_{(66-230)}$ in pGBKT7 & Clontech \\
\hline pGA2853c & pGADT7-Rv2853c full orf & This study \\
\hline pGB3286c & pGBKT7-Rv3286c full orf & Parida et al, 2005 \\
\hline pGA3287c & pGADT7-Rv3287c full orf & Parida et al, 2005 \\
\hline pGB2440c & pGBKT7-Rv2440c full orf & This study \\
\hline
\end{tabular}


bound Obg protein $\left(\mathrm{His}_{10} \mathrm{Obg}\right)$ was eluted with $2 \mathrm{ml}$ of elution buffer $\left(50 \mathrm{mM} \mathrm{NaH}_{2} \mathrm{PO}_{4} \mathrm{pH} 8.0,300 \mathrm{mM} \mathrm{NaCl}\right.$, $250 \mathrm{mM}$ Imidazole). The eluted fraction was dialyzed against $2 \mathrm{~L}$ of $20 \mathrm{mM}$ Tris- $\mathrm{HCl} \mathrm{pH} 8.0$ containing 5\% glycerol. About $100 \mu \mathrm{g}$ of the resulting purified Obg was used to immunize a single rabbit to generate polyclonal antiserum, according to standard protocols. The rabbit received two booster doses of similar amounts of protein at two week intervals before collecting the serum two weeks after the last booster dose.

\section{GTP crosslinking}

Crosslinking of the Obg protein with GTP was done by mixing Ni-NTA-purified M. tuberculosis His-tagged Obg $\left(\mathrm{His}_{10}-\mathrm{Obg}\right)(5 \mu \mathrm{g})$ with a $40 \mu \mathrm{l}$ cross-linking mixture $\left(20 \mu \mathrm{Ci}\right.$ of $\left[\alpha^{32} \mathrm{P}\right]$-dGTP, $1 \mathrm{mM}$ ATP, $50 \mathrm{mM}$ Tris $\mathrm{HCl}$ (pH 8.0), $100 \mathrm{mM} \mathrm{NaCl}, 5 \mathrm{mM} \mathrm{MgCl}_{2}$ and $1 \%$ Triton $\mathrm{X}-100)$. Eppendorf tubes containing the mixture were kept for $1 \mathrm{~h}$ at $4^{\circ} \mathrm{C}$ in a dark chamber, and then placed on ice over a Petri dish to expose them to UV light $(256 \mathrm{~nm})$ for different time periods. Crosslinking of Obg with GTP was assessed after separating the crosslinked complexes on SDS-PAGE, transferring the proteins from the gel onto nitrocellulose membranes, and exposure of the membranes to X-ray film to detect the presence of ${ }^{32} \mathrm{P}$ in the protein bands.

\section{GTPase activity of Obg}

To determine whether $M$. tuberculosis can hydrolyze GTP, we added $\left[\gamma_{-}{ }^{32} \mathrm{P}\right]$ GTP to purified $\mathrm{His}_{10-} \mathrm{Obg}$, following the method of Welsh et al [13]. The reactions were conducted in $100 \mu \mathrm{l}$ volumes containing $50 \mathrm{mM}$ Tris $\mathrm{pH}$ 8.5, $0.1 \mathrm{mM}$ EDTA, $1.5 \mathrm{mM} \mathrm{MgCl}_{2}, 200 \mathrm{mM}$ $\mathrm{KCl}, 10 \%$ glycerol, $25 . \mu \mathrm{Ci}$ of $\left[\gamma^{32} \mathrm{P}\right] \mathrm{GTP}$ and $7 \mu \mathrm{g}$ of $\mathrm{His}_{10}$-Obg. These reactions were incubated at $37^{\circ} \mathrm{C}$ for $3 \mathrm{~h}$, and then terminated by the addition of 700. $\mu 1$ of ice cold 20.mM phosphoric acid (pH2. 0) containing 5\% activated charcoal. The charcoal was sedimented by centrifugation, and $100 \mu \mathrm{l}$ of the remaining supernatant used to measure the ${ }^{32} \mathrm{P}_{\mathrm{i}}$ released. GTPase activity was expressed as ${ }^{32} \mathrm{P}_{\mathrm{i}}$ released $(\mathrm{cpm}) / \mu \mathrm{g}$ protein/hour.

\section{Autophosphorylation assay}

To determine whether $M$. tuberculosis Obg is autophosphorylated in the presence of GTP, $\mathrm{His}_{10}$-Obg $(5 \mu \mathrm{g})$ was incubated with $10 . \mu \mathrm{Ci}$ of $\left[\gamma_{-}{ }^{32} \mathrm{P}\right] \mathrm{GTP}$ in a $25 \mu \mathrm{l}$ reaction mixture containing $50 \mathrm{mM}$ Tris- $\mathrm{HCl} \mathrm{pH} 8.0$, $0.1 \mathrm{mM}$ EDTA, $1.5 \mathrm{mM} \mathrm{MgCl}_{2}, 100 \mathrm{mM} \mathrm{KCl}$ and $10 \%$ glycerol at $37^{\circ} \mathrm{C}$. The reactions were arrested at different time points by the addition of SDS-PAGE sample buffer. The samples from different time points were subjected to SDS-PAGE and transferred to nitrocellulose membranes, and autophosphorylation of the Obg protein was visualized by autoradiography.

\section{Soluble and membrane fractions}

Soluble and membrane fractions of $M$. tuberculosis were prepared as described [47]. Briefly, M. tuberculosis cells were grown to $0.6-1.0 \mathrm{OD}$ (at $600 \mathrm{~nm}$ ) in $400 \mathrm{ml}$ of 7H9-OADC-TW broth. The cells were then harvested by centrifugation at $5,000 \mathrm{~g}$. The pellet was resuspended in $25 \mathrm{ml}$ of $20 \mathrm{mM}$ sodium phosphate- $10 \mathrm{mM}$ EDTA ( $\mathrm{pH}$ 7.0) buffer, and spun again at 5,000 g to remove the medium completely. The pellet was then suspended in $4 \mathrm{ml}$ of $20 \mathrm{mM}$ sodium phosphate- $10 \mathrm{mM}$ EDTA buffer containing a protease inhibitor cocktail (Sigma), and divided into four $2 \mathrm{ml}$ screw cap tubes with O-rings containing silica beads. The tubes were cooled on ice, and then the cells were disrupted using a bead beater for two 1-min cycles, with a 30 second interval between them. The tubes were chilled on ice for $5 \mathrm{~min}$ and then centrifuged at $12,000 \mathrm{~g}$ at $4^{\circ} \mathrm{C}$ for $15 \mathrm{~min}$. The resulting supernatants were pooled, transferred to $4 \mathrm{ml}$ centrifuge tubes and spun at $49,000 \mathrm{~g}$ for $4 \mathrm{~h}$ at $4^{\circ} \mathrm{C}$. These supernatants (soluble fraction) were transferred to fresh tubes for analysis, while the pellet (membrane fraction) was washed once with $4 \mathrm{ml}$ of $20 \mathrm{mM}$ sodium phosphate-10 $\mathrm{mM}$ EDTA buffer and resuspended in $0.5 \mathrm{ml}$ of the same buffer. Protein concentrations in both the soluble and membrane fractions, and in the unseparated lysates, were determined by the BCA method (Pierce) before subjecting them to electrophoresis.

\section{Preparation of ribosomal fractions}

M. tuberculosis $\mathrm{H} 37 \mathrm{Rv}$ cells were grown in $100 \mathrm{ml}$ of $7 \mathrm{H} 9-\mathrm{TW}-\mathrm{OADC}$ broth at $37^{\circ} \mathrm{C}$. When the OD of the cultures reached to $0.6-1.0$ (at $600 \mathrm{~nm}$ ), the cells were harvested by centrifugation, resuspended in $2 \mathrm{ml}$ of buffer A (10 mM Tris- $\mathrm{HCl}, \mathrm{pH} 7.6,10 \mathrm{mM}$ magnesium acetate, $100 \mathrm{mM}$ ammonium acetate, $6 \mathrm{mM} \beta$ mercaptoethanol, and $2 \mathrm{mM}$ PMSF), and disrupted by bead beating as described earlier. The lysate was then centrifuged at 12,000 g for $15 \mathrm{~min}$. The clear supernatant was collected and its protein concentration determined. About $500 \mu \mathrm{g}$ of this protein was loaded onto a $10-40 \%$ sucrose gradient (total volume $4 \mathrm{ml}$ ) made in buffer B (10 mM Tris- $\mathrm{HCl}, \mathrm{pH}$ 7.6, $1 \mathrm{mM}$ magnesium acetate, $100 \mathrm{mM}$ ammonium acetate, $6 \mathrm{mM} \beta$-mercaptoethanol, and $2 \mathrm{mM}$ PMSF). The gradient was centrifuged at 90,000 g for $20 \mathrm{~h}$. The gradients were then aliquoted into $250 \mu \mathrm{l}$ fractions, and the absorbance of each fraction measured (manually) at $260 \mathrm{~nm}$. Magnesium acetate $(10 \mu \mathrm{l}$ of $1 \mathrm{M})$ was added to each fraction to increase the concentration of magnesium ions to $20 \mathrm{mM}$. The fractions were then mixed with equal amounts of $100 \%$ of ice-cold ethanol, and their proteins precipitated overnight at $-80^{\circ} \mathrm{C}$. The precipitates were collected by centrifugation at $12,000 \mathrm{~g}$ for $30 \mathrm{~min}$. The pellets were resuspended in $100 \mu \mathrm{l}$ of buffer A. Forty $\mu \mathrm{l}$ 
of the suspension from each fraction was mixed with $10 \mu \mathrm{l} 4 \times$ loading buffer and boiled, after which $25 \mu \mathrm{l}$ of each sample was loaded onto each well for SDS-PAGE. After electrophoresis, the proteins were transferred to nitrocellulose membranes, probed with anti-Obg antiserum, and the blots probed by ECL chemiluminescence method (Amersham). Association of Obg with ribosomal subunits was determined by comparing the immunoblot for each fraction with its absorbance at $260 \mathrm{~nm}$.

\section{Yeast two-hybrid assay}

Protein-protein interactions were performed using the Matchmaker Gal4 two-hybrid system 3 (Clontech, Palo Alto, CA) as described previously [42]. The yeast strain AH109, which has the reporter genes ADE2 (adenine), HIS3 (histidine), and MEL1 ( $\alpha$-galactosidase), was used as the host strain. Yeast plasmids (Table 2) were transformed into AH109 in appropriate combinations (Table 1) using standard protocols provided by Clontech. Expression of proteins by plasmids created for yeast two-hybrid analysis was assessed by the TNT Quick transcription and translation system (Promega), before transformation of the plasmids into yeast. Protein-protein interactions were determined by positive growth of yeast in synthetic drop out medium (SD) plates lacking adenine and histidine, and by the presence of blue color, which identifies $\alpha$-galactosidase activity. To rule out false activation of the reporter gene, we transformed each of the constructs separately into yeast strain $\mathrm{AH} 109$, and assessed reporter gene activation. The strength of the interaction was verified by measuring the $\alpha$-galactosidase released into the growth medium, again using protocols provided by Clontech.

\section{SDS-PAGE and immunoblot}

SDS-PAGE and immunoblotting were performed following the methods of Ausubel et al [45]. Protein contents in extracts of E. coli or M. tuberculosis, obtained through sonication or bead-beating techniques, were determined by BCA (bicinchoninic acid) method (Pierce). Proteins were separated on 12\% SDS-PAGE and transferred to nitrocellulose membranes. The blots were probed with rabbit anti-M. tuberculosis Obg antiserum (1:500 dilution) or rabbit anti-M. tuberculosis SigH antiserum (1:1000), developed against recombinant $\mathrm{His}_{10-} \mathrm{Obg}$ or $\mathrm{His}_{10-} \mathrm{SigH}$ proteins, respectively. Alkaline phosphatase-conjugated anti-rabbit IgG (Zymed, 1:1000 dilution) or peroxidase-conjugated anti-rabbit IgG (Sigma, 1:10,000 dilution) were used as secondary antibodies. The blots were developed either with 5-bromo-4-chloro-3-indolyl phosphate (BCIP)/ nitroblue tetrazolium (NBT) substrate (Sigma, for alkaline phosphatase), or with an ECL kit (Amersham, for peroxidase).

\section{Additional material}

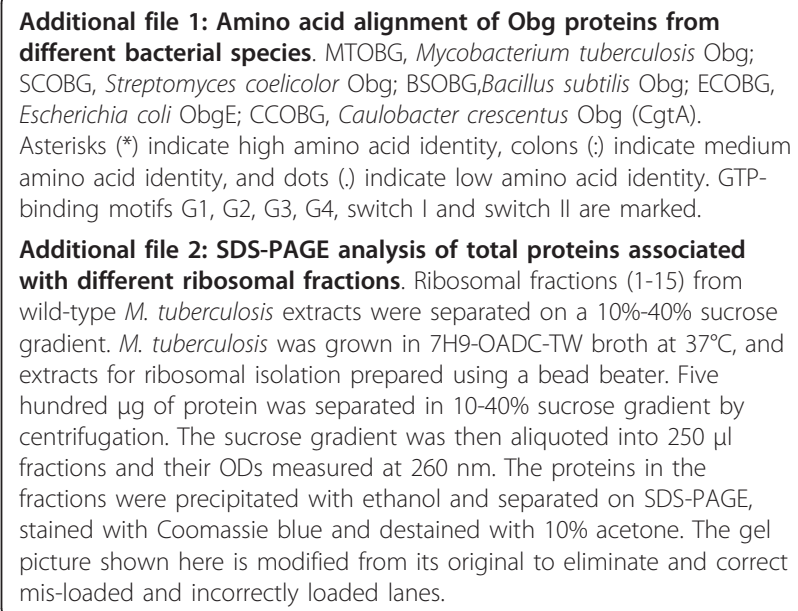

Additional file 2: SDS-PAGE analysis of total proteins associated with different ribosomal fractions. Ribosomal fractions (1-15) from wild-type $M$. tuberculosis extracts were separated on a $10 \%-40 \%$ sucrose gradient. M. tuberculosis was grown in $7 \mathrm{H} 9-\mathrm{OADC}-\mathrm{TW}$ broth at $37^{\circ} \mathrm{C}$, and extracts for ribosomal isolation prepared using a bead beater. Five hundred $\mu \mathrm{g}$ of protein was separated in $10-40 \%$ sucrose gradient by centrifugation. The sucrose gradient was then aliquoted into $250 \mu \mathrm{l}$ fractions and their ODs measured at $260 \mathrm{~nm}$. The proteins in the fractions were precipitated with ethanol and separated on SDS-PAGE, stained with Coomassie blue and destained with 10\% acetone. The gel picture shown here is modified from its original to eliminate and correct mis-loaded and incorrectly loaded lanes.

\section{Acknowledgements}

This study was partly supported by Institutional Research Grant and San Antonio Area foundation.

\section{Authors' contributions}

SJS performed the construction of plasmids and isolation of ribosomal fractions. SS carried out the overexpression of Obg and its biochemical analysis. VLS read the manuscript critically, participated in interpretation of the data, and worked with the other authors to prepare the final version of the paper. SD conceived the study, participated in its design and interpretation of results and wrote the manuscript. All authors read and approved the manuscript.

Received: 18 August 2010 Accepted: 25 February 2011 Published: 25 February 2011

\section{References}

1. Bourne HR, Sanders DA, McCormick F: The GTPase superfamily: a conserved switch for diverse cell functions. Nature 1990, 348(6297):125-132.

2. Kaziro $Y$, Itoh $H$, Kozasa $T$, Nakafuku M, Satoh T: Structure and function of signal-transducing GTP-binding proteins. Annu Rev Biochem 1991, 60:349-400.

3. Bourne HR, Sanders DA, McCormick F: The GTPase superfamily: conserved structure and molecular mechanism. Nature 1991, 349(6305):117-127.

4. Sprang SR: G protein mechanisms: insights from structural analysis. Annu Rev Biochem 1997, 66:639-678.

5. Pandit SB, Srinivasan N: Survey for g-proteins in the prokaryotic genomes: prediction of functional roles based on classification. Proteins 2003, 52:585-597.

6. Hirano Y, Ohniwa RL, Wada C, Yoshimura SH, Takeyasu K: Human small G proteins, $\mathrm{ObgH} 1$, and $\mathrm{ObgH} 2$, participate in the maintenance of mitochondria and nucleolar architectures. Genes Cells 2006, 11:1295-1304.

7. Ferrari FA, Trach K, Hoch JA: Sequence analysis of the spoOB locus reveals a polycistronic transcription unit. J Bacterio/ 1985, 161(2):556-562.

8. Okamoto S, Itoh M, Ochi K: Molecular cloning and characterization of the obg gene of Streptomyces griseus in relation to the onset of morphological differentiation. J Bacterio/ 1997, 179(1):170-179. 
9. Okamoto S, Ochi K: An essential GTP-binding protein functions as a regulator for differentiation in Streptomyces coelicolor. Mol Microbiol 1998 30(1):107-119.

10. Maddock J, Bhatt A, Koch M, Skidmore J: Identification of an essential Caulobacter crescentus gene encoding a member of the Obg family of GTP-binding proteins. J Bacteriol 1997, 179(20):6426-6431.

11. Kobayashi G, Moriya S, Wada C: Deficiency of essential GTP-binding protein ObgE in Escherichia coli inhibits chromosome partition. Mol Microbiol 2001, 41(5):1037-1051.

12. Czyz A, Zielke R, Konopa G, Wegrzyn G: A Vibrio harveyi insertional mutant in the cgtA (obg, yhbZ) gene, whose homologues are present in diverse organisms ranging from bacteria to humans and are essential genes in many bacterial species. Microbiology 2001, 147(Pt 1):183-191.

13. Welsh KM, Trach KA, Folger C, Hoch JA: Biochemical characterization of the essential GTP-binding protein Obg of Bacillus subtilis. J Bacteriol 1994, 176(23):7161-7168.

14. Kok J, Trach KA, Hoch JA: Effects on Bacillus subtilis of a conditional lethal mutation in the essential GTP-binding protein Obg. J Bacterio/ 1994, 176(23):7155-7160

15. Vidwans SJ, Ireton K, Grossman AD: Possible role for the essential GTPbinding protein $\mathrm{Obg}$ in regulating the initiation of sporulation in Bacillus subtilis. J Bacterio/ 1995, 177(11):3308-3311.

16. Buglino J, Shen V, Hakimian P, Lima CD: Structural and biochemical analysis of the Obg GTP binding protein. Structure 2002, 10(11):1581-1592.

17. Chatterji D, Ojha AK: Revisiting the stringent response, ppGpp and starvation signaling. Curr Opin Microbio/ 2001, 4(2):160-165.

18. Magnusson LU, Farewell A, Nystrom T: ppGpp: a global regulator in Escherichia coli. Trends Microbiol 2005, 13(5):236-242.

19. Jiang M, Sullivan SM, Wout PK, Maddock JR: G-protein control of the ribosome-associated stress response protein SpoT. J Bacteriol 2007, 189(17):6140-6147.

20. Wout P, Pu K, Sullivan SM, Reese V, Zhou S, Lin B, Maddock JR: The Escherichia coli GTPase CgtAE cofractionates with the $50 \mathrm{~S}$ ribosomal subunit and interacts with SpoT, a ppGpp synthetase/hydrolase. J Bacteriol 2004, 186(16):5249-5257.

21. Raskin DM, Judson N, Mekalanos JJ: Regulation of the stringent response is the essential function of the conserved bacterial G protein CgtA in Vibrio cholerae. Proc Natl Acad Sci USA 2007, 104(11):4636-4641.

22. Rankin S, Li Z, Isberg RR: Macrophage-induced genes of Legionella pneumophila: protection from reactive intermediates and solute imbalance during intracellular growth. Infect Immun 2002 70(7):3637-3648

23. Scott JM, Ju J, Mitchell T, Haldenwang WG: The Bacillus subtilis GTP binding protein obg and regulators of the sigma(B) stress response transcription factor cofractionate with ribosomes. J Bacteriol 2000 182(10):2771-2777

24. Lin B, Thayer DA, Maddock JR: The Caulobacter crescentus CgtAC protein cosediments with the free $50 \mathrm{~S}$ ribosomal subunit. J Bacteriol 2004, 186(2):481-489.

25. Sikora AE, Zielke R, Datta K, Maddock JR: The Vibrio harveyi GTPase CgtAV is essential and is associated with the $50 \mathrm{~S}$ ribosomal subunit. J Bacteriol 2006, 188(3):1205-1210.

26. Sato A, Kobayashi G, Hayashi H, Yoshida H, Wada A, Maeda M, Hiraga S, Takeyasu K, Wada C: The GTP binding protein Obg homolog ObgE is involved in ribosome maturation. Genes Cells 2005, 10(5):393-408.

27. WHO: Global tuberculosis control. A short update to the 2009 report 2009.

28. Sassetti CM, Boyd DH, Rubin EJ: Genes required for mycobacterial growth defined by high density mutagenesis. Mol Microbiol 2003, 48(1):77-84.

29. Comartin DJ, Brown ED: Non-ribosomal factors in ribosome subunit assembly are emerging targets for new antibacterial drugs. Curr Opin Pharmacol 2006, 6(5):453-458.

30. Anurag M, Dash D: Unraveling the potential of intrinsically disordered proteins as drug targets: application to Mycobacterium tuberculosis. Mol Biosyst 2009, 5(12):1752-1757.

31. March PE, Inouye M: GTP-binding membrane protein of Escherichia coli with sequence homology to initiation factor 2 and elongation factors Tu and G. Proc Natl Acad Sci USA 1985, 82(22):7500-7504.

32. Lin B, Covalle KL, Maddock JR: The Caulobacter crescentus CgtA protein displays unusual guanine nucleotide binding and exchange properties. $J$ Bacteriol 1999, 181(18):5825-5832.
33. John J, Frech M, Wittinghofer A: Biochemical properties of Ha-ras encoded p21 mutants and mechanism of the autophosphorylation reaction. J Biol Chem 1988, 263(24):11792-11799.

34. Sood P, Lerner CG, Shimamoto T, Lu Q, Inouye M: Characterization of the autophosphorylation of Era, an essential Escherichia coli GTPase. Mol Microbiol 1994, 12(2):201-208

35. Malen H, Pathak S, Softeland T, de Souza GA, Wiker HG: Definition of nove cell envelope associated proteins in Triton X-114 extracts of Mycobacterium tuberculosis H37Rv. BMC Microbiol 2010, 10:132.

36. Wolfe LM, Mahaffey SB, Kruh NA, Dobos KM: Proteomic definition of the cell wall of Mycobacterium tuberculosis. J Proteome Res 2010, 9(11):5816-5826.

37. Datta K, Skidmore JM, Pu K, Maddock JR: The Caulobacter crescentus GTPase CgtAC is required for progression through the cell cycle and for maintaining $50 \mathrm{~S}$ ribosomal subunit levels. Mol Microbiol 2004, 54(5):1379-1392.

38. Tan J, Jakob U, Bardwell JC: Overexpression of two different GTPases rescues a null mutation in a heat-induced rRNA methyltransferase. J Bacteriol 2002, 184(10):2692-2698.

39. Datta K, Fuentes JL, Maddock JR: The yeast GTPase Mtg2p is required for mitochondrial translation and partially suppresses an rRNA methyltransferase mutant, mrm2. Mol Biol Cell 2005, 16(2):954-963.

40. Lapik YR, Misra JM, Lau LF, Pestov DG: Restricting conformational flexibility of the switch II region creates a dominant-inhibitory phenotype in Obg GTPase Nog1. Mol Cell Biol 2007, 27(21):7735-7744.

41. Scott JM, Haldenwang WG: Obg, an essential GTP binding protein of Bacillus subtilis, is necessary for stress activation of transcription factor sigma(B). J Bacteriol 1999, 181(15):4653-4660.

42. Parida BK, Douglas T, Nino C, Dhandayuthapani S: Interactions of antisigma factor antagonists of Mycobacterium tuberculosis in the yeast twohybrid system. Tuberculosis (Edinb) 2005, 85(5-6):347-355.

43. Beaucher J, Rodrigue S, Jacques PE, Smith I, Brzezinski R, Gaudreau L: Novel Mycobacterium tuberculosis anti-sigma factor antagonists control sigmaF activity by distinct mechanisms. Mol Microbiol 2002, 45(6):1527-1540.

44. Hecker M, Volker U: General stress response of Bacillus subtilis and other bacteria. Adv Microb Physiol 2001, 44:35-91.

45. Ausubel F, Brent R, Kingston R, Moore D, Seidman J, Smith J, Struhl K: Current Prtocols in Molecular Biology. New York: Wiley; 1989.

46. Stover CK, de la Cruz VF, Fuerst TR, Burlein JE, Benson LA, Bennett LT, Bansal GP, Young JF, Lee MH, Hatfull GF, et al: New use of BCG for recombinant vaccines. Nature 1991, 351(6326):456-460.

47. Mueller-Ortiz SL, Wanger AR, Norris SJ: Mycobacterial protein HbhA binds human complement component C3. Infect Immun 2001, 69(12):7501-7511.

doi:10.1186/1471-2180-11-43

Cite this article as: Sasindran et al:: Biochemical and physiological characterization of the GTP-binding protein Obg of Mycobacterium tuberculosis. BMC Microbiology 2011 11:43.

\section{Submit your next manuscript to BioMed Central and take full advantage of:}

- Convenient online submission

- Thorough peer review

- No space constraints or color figure charges

- Immediate publication on acceptance

- Inclusion in PubMed, CAS, Scopus and Google Scholar

- Research which is freely available for redistribution

Submit your manuscript at www.biomedcentral.com/submit
C Biomed Central 